\title{
Impact of Conception Method on Twin Pregnancy Course and Outcome
}

\author{
Auswirkungen der Konzeptionsmethode auf Verlauf und Ergebnis \\ von Zwillingsschwangerschaften
}

Authors

Affiliations
S. Andrijasevic ${ }^{1}$, J. Dotlic ${ }^{2}$, S. Aksam¹ , J. Micic ${ }^{2}$, M. Terzic $^{2}$

${ }^{1}$ Clinic of Obstetrics and Gynecology, Clinical Center of Serbia, Belgrade, Serbia

${ }^{2}$ Clinic of Obstetrics and Gynecology, Clinical Center of Serbia, Medical Faculty, University of Belgrade, Belgrade, Serbia
Key words

- assisted reproductive technology (ART)

- pregnancy

- spontaneous conception

- pregnancy outcome

twins

Schlüsselwörter

- assistierte Reproduktion

- Schwangerschaft

- Spontankonzeption

- Ausgang der

Schwangerschaft

- Zwillinge $\begin{array}{ll}\text { received } & 24.4 .2014 \\ \text { revised } & 1.9 .2014 \\ \text { accepted } & 12.9 .2014\end{array}$

Bibliography

DOI http://dx.doi.org/

10.1055/s-0034-1383148

Geburtsh Frauenheilk 2014; 74:

933-939 @ Georg Thieme

Verlag KG Stuttgart · New York .

ISSN 0016-5751

\section{Correspondence}

Dr. Jelena Dotlic

Clinic of Obstetrics

and Gynecology

Clinical Center of Serbia,

Medical Faculty, University

of Belgrade

Dr Koste Todorovica 26

Belgrade

Serbia

enadot@yubc.net

\section{Abstract}

$\nabla$

Objective: The aim of the study was to investigate the course and outcomes of twin pregnancies conceived by different methods of assisted reproduction (ART) compared to those conceived spontaneously.

Methods: The study involved patients with twin pregnancies who delivered at the Ob/Gyn Clinic of the Clinical Center of Serbia over a period of three years. Patients were differentiated according to method of conception and type of ART. Age, parity, etiology of infertility, pregnancy complications, time of membrane rupture and type of delivery was recorded for each patient. Gestational week at delivery, presentation, birth weight, Apgar score, chorionicity and accompanying disorders were separately recorded for each twin. The data were analyzed statistically.

Results: A total of 431 patients were included in the study. Although more twins were conceived by ART, the difference was not statistically significant $(p=0.092)$. The most common ART procedure was IVF/ICSI $(\mathrm{p}=0.001)$. ART procedures, particularly IVF/ICSI, were significantly correlated with more advanced maternal age, fewer previous pregnancies and delivery by cesarean sections, usually planned $(\mathrm{p}=0.001)$. Preterm membrane rupture was more common after ICSI, but preterm delivery and pregnancy complications were infrequent, irrespective of the method of conception ( $p=0.001)$. ART twins were mostly dichorionic $(p=0.036)$. Monochorionic twins were conceived either spontaneously or with ICSI. Conception by ART was not correlated with twins' outcome (weight, Apgar score, disorders).

Conclusions: ART procedures do not have a negative impact on twin pregnancy course and outcome. Twin pregnancies conceived spontaneously or by ART have similar outcomes.

\section{Zusammenfassung \\ $\nabla$}

Zielsetzung: Die vorliegende Studie untersucht den Verlauf und die Ergebnisse von Zwillingsschwangerschaften bei nach verschiedenen Methoden der assistierten Reproduktion (ART) konzipierten Zwillingen verglichen mit spontan konzipierten Zwillingen.

Methoden: Patientinnen mit Zwillingsschwangerschaften, die in der Frauenklinik des Klinikums von Serbien innerhalb eines Zeitraums von 3 Jahren entbunden hatten, wurden in die Studie aufgenommen. Die Patientinnen wurden je nach Konzeptionsmodus und ART-Methode in verschiedene Gruppen eingeteilt. Alter, vorangehende Schwangerschaften, Gründe der Unfruchtbarkeit, Schwangerschaftskomplikationen, Zeitpunkt des Blasensprungs und Entbindungsmodus jeder Patientin wurden vermerkt. Gestationswoche bei der Geburt, Kindslage, Geburtsgewicht, ApgarWerte, Chorionizität sowie Komorbiditäten wurden für jedes Neugeborene separat vermerkt. Die gewonnenen Daten wurden einer statistischen Analyse unterzogen.

Ergebnisse: Insgesamt 431 Patientinnen nahmen an der Studie teil. Obwohl die Gruppe von ARTkonzipierten Zwillingen größer war, war dieser Unterschied statistisch nicht signifikant $(p=0,092)$. Die am häufigsten verwendete Methode zur assistierten Reproduktion war IVF/ICSI ( $p=0,001)$. ART-Verfahren, insbesondere IVF/ICSI, korrelierten signifikant mit höherem mütterlichem Alter, geringerer Anzahl vorangegangener Schwangerschaften und geplanter Sectio-Entbindung $(p=0,001)$. Vorzeitiger Blasensprung war häufiger nach ICSI, aber vorzeitige Entbindung sowie Schwangerschaftskomplikationen waren in allen Gruppen selten $(p=0,001)$. ART-konzipierte Zwillinge waren meist dichorial $(p=0,036)$. Monochoriale Zwillinge entwickelten sich entweder nach Spontankonzeption oder ICSI. Es gab keine Korrelation zwischen assistierter Re- 
produktion und Entwicklung der Zwillinge (Geburtsgewicht, Apgar-Werte, Morbidität).

Schlussfolgerungen: ART-Verfahren haben keine negative Auswirkung auf Verlauf und Ergebnis von Zwillingsschwangerschaften. Die Ergebnisse für Zwillingsschwangerschaften nach Spontankonzeption bzw. ART sind gleichwertig.

\section{Introduction}

$\nabla$

In the last decade, the number of multiple pregnancies occurring worldwide has increased. The main contributors to this rise include increasing maternal age and the use of ovulation stimulation in assisted reproductive technologies (ART). There is an ongoing debate about the risk of twin pregnancies after assisted reproduction. Dual embryo transfer has been the standard for many years [1]. It is estimated that pregnancies resulting from ART procedures account for $0.2-3.9 \%$ of births in Europe [2]. Attitudes toward multiple pregnancies and pregnancy complications differ between infertile and fertile women. Patients who are treated for infertility with ART usually have a greater desire for twins in order to increase the success rate of ART [3]. Risks associated with multiple pregnancies are more acceptable to infertile women, and only a quarter of infertile patients agree to the transfer of only one embryo [1]. Careful monitoring and management of twin pregnancies is the basis of modern perinatology because multiple pregnancies carry an increased risk of perinatal morbidity and mortality compared with singleton pregnancies [2]. This risk is the result of complications such as premature birth, fetal growth restriction, preeclampsia, etc. $[4,5]$. ART twins have considerably higher risks compared to ART singletons with regard to most short and long-term outcomes [6,7]. Thus, high twin birth rates and adverse outcomes in twins are still a major concern in ART [1]. However, previous studies have shown that twins conceived by ART have similar physical and neurological development to those of twins conceived naturally. Moreover, the incidence of pregnancy complications in multiple pregnancies was found to be comparable, irrespective of the method of conception $[2,8]$.

The aim of this study was to investigate the course and outcomes of twin pregnancies conceived by assisted reproduction (ART) compared to twin pregnancies conceived spontaneously.

\section{Materials and Methods \\ $\nabla$}

\section{Recruitment of study population}

The study involved patients with twin pregnancies who delivered at the Clinic of Gynecology and Obstetrics, Clinical Center of Serbia between January 1, 2011 and December 31, 2013. Patients were divided into two groups according to the method of conception (spontaneous or ART).

\section{Assessment of clinical data}

Age, parity, illnesses in pregnancy and type/nature of the illness (hypertension [HTA], diabetes mellitus [DM], placental abruption or placenta praevia, other diseases and simultaneous associated comorbidities), etiology of infertility (male, tubal, ovarian insufficiency, endometriosis, immunological, unknown and combined), time of membrane rupture (spontaneous premature preterm rupture of membranes [PPROM] or rupture in hospital after the start of contractions) and type of delivery (vaginal or cesarean) were recorded for each patient. Type of ART (only in vitro fertilization [IVF], IVF/ICSI [intracytoplasmic sperm injection] or IUI [intrauterine insemination]) was also noted for each patient. Weeks of gestation at delivery, presentation, gender, weight, Apgar score, chorionicity and morbidity (intrauterine growth restriction [IUGR], malformations, asphyxiation, comorbidities and other disorders) were recorded for each twin. Pregnancy outcome was considered excellent if both twins had Apgar scores above eight (Apgar I + Apgar II > 16), intermediate if Apgar I + Apgar II was between 10 and 16, while the outcome was considered bad if Apgar I + Apgar II was $<10$.

The data were compared between the groups of patients with and without ART as well as between the types of ART. Every patient gave informed consent for all procedures upon admission to the Clinic. The study was approved by the Clinic Board.

\section{Statistical analysis}

Statistical analysis was done using descriptive and analytical statistics (percentages, $\mathrm{X}^{2}$ test, Kruskal-Wallis test and correlations) using the SPSS program, version 15. Binary logistic regression was done to test for a possible relationship between assessed characteristics of mothers and twins and conception by ART. Finally, Receiver Operator Curve (ROC) analysis was performed for parameters that correlated significantly with ART use for conception.

\section{Results}

$\nabla$

\section{Characteristics of investigated women}

Parameters of pregnant women and their pregnancies for the overall group and according to type of conception (spontaneous, ART) are presented in $\bullet$ Table 1 . The same parameters differentiated according to ART type are shown in $\bullet$ Table 2.

The study included 431 patients with twin pregnancies. The mean age of the women was $32.99 \pm 6.46$ years ( minimum $=17$ years; maximum $=43$ years). The majority of women were primiparous. The most frequent cause of infertility was male.

\section{Delivery time and mode}

Delivery mostly occurred in the 36 th gestational week (minimum $=25$; maximum $=40 ;$ mean $\pm S D=35.42 \pm 2.80$ ). Only 18 patients delivered before the 30th gestational week. $33.2 \%$ of women gave birth after the 38th gestational week. Although more women had cesarean sections, the incidence of planned and urgent operative deliveries was similar.

\section{Pregnancy complications and treatment}

Hypertensive disorders were the most common, but the majority of mothers had no pregnancy-related disease. Only a few women $(\mathrm{n}=30)$ had pre-existing medical conditions, mostly diabetes. However, more than half of the patients received a combined therapy for pregnancy support, and almost $90 \%$ of women received some kind of medication during pregnancy. 
Table 1 Parameters of pregnant women and their pregnancies for the overall group and according to type of conception (spontaneous, ART).

\begin{tabular}{|c|c|c|c|c|c|c|c|}
\hline \multirow[t]{3}{*}{ Parameters } & & \multirow{2}{*}{\multicolumn{2}{|c|}{ Whole group }} & \multicolumn{4}{|l|}{ ART } \\
\hline & & & & \multicolumn{2}{|l|}{ No } & \multicolumn{2}{|l|}{ Yes } \\
\hline & & Number & $\%$ & Number & $\%$ & Number & $\%$ \\
\hline \multirow[t]{4}{*}{ Parity } & 1 & 335 & 77.7 & 120 & 27.84 & 215 & 49.88 \\
\hline & 2 & 68 & 15.8 & 51 & 11.83 & 17 & 3.94 \\
\hline & 3 & 15 & 3.5 & 14 & 3.25 & 1 & 0.23 \\
\hline & more & 13 & 3.1 & 13 & 3.02 & 0 & 0.00 \\
\hline \multirow{7}{*}{ Cause of infertility } & male & 67 & 28.7 & 0 & 0.00 & 67 & 28.76 \\
\hline & tubal & 53 & 22.7 & 0 & 0.00 & 53 & 22.75 \\
\hline & immunologic & 4 & 1.7 & 0 & 0.00 & 4 & 1.72 \\
\hline & ovarian insufficiency & 5 & 2.1 & 0 & 0.00 & 5 & 2.15 \\
\hline & endometriosis & 25 & 10.7 & 0 & 0.00 & 25 & 10.73 \\
\hline & combined & 36 & 15.5 & 0 & 0.00 & 36 & 15.45 \\
\hline & unknown & 43 & 18.5 & 0 & 0.00 & 43 & 18.45 \\
\hline \multirow[t]{2}{*}{ PPROM } & no & 327 & 75.9 & 157 & 36.43 & 170 & 39.44 \\
\hline & yes & 104 & 24.1 & 41 & 9.51 & 63 & 14.62 \\
\hline \multirow[t]{2}{*}{ Amniotic fluid } & clear & 399 & 92.6 & 187 & 43.39 & 212 & 49.19 \\
\hline & not clear & 32 & 7.4 & 11 & 2.55 & 21 & 4.87 \\
\hline \multirow[t]{3}{*}{ Delivery type } & vaginal & 175 & 40.6 & 146 & 33.87 & 29 & 6.73 \\
\hline & planned CS & 149 & 34.6 & 30 & 6.96 & 119 & 27.61 \\
\hline & urgent CS & 107 & 24.8 & 22 & 5.10 & 85 & 19.72 \\
\hline \multirow[t]{6}{*}{ Maternal comorbidities } & none & 243 & 56.4 & 110 & 25.52 & 133 & 30.86 \\
\hline & hypertension & 58 & 13.5 & 31 & 7.19 & 27 & 6.26 \\
\hline & diabetes & 21 & 4.9 & 5 & 1.16 & 16 & 3.71 \\
\hline & placental & 8 & 1.9 & 4 & 0.93 & 4 & 0.93 \\
\hline & other & 64 & 14.8 & 31 & 7.19 & 33 & 7.66 \\
\hline & multiple & 37 & 8.6 & 17 & 3.94 & 20 & 4.64 \\
\hline \multirow[t]{5}{*}{ Supportive therapy } & no & 45 & 10.4 & 22 & 5.10 & 23 & 5.34 \\
\hline & progesterone & 6 & 1.4 & 1 & 0.23 & 5 & 1.16 \\
\hline & antibiotics & 25 & 5.8 & 12 & 2.78 & 13 & 3.02 \\
\hline & combined & 284 & 65.9 & 127 & 29.47 & 157 & 36.43 \\
\hline & other & 71 & 16.5 & 36 & 8.35 & 35 & 8.12 \\
\hline \multirow[t]{2}{*}{ Cerclage } & no & 379 & 87.9 & 172 & 39.91 & 207 & 48.03 \\
\hline & yes & 52 & 12.1 & 26 & 6.03 & 26 & 6.03 \\
\hline
\end{tabular}

ART: assisted reproductive technology; PPROM: premature preterm rupture of membranes; CS: cesarean section

Preterm membrane rupture was relatively rare and amniotic fluid was usually normal. Cerclage and maturation of fetal lungs were usually not done.

\section{Characteristics of assessed twins}

Parameters of twins for the whole group and differentiated according to method of conception (spontaneous, ART) are shown in Table 3. Parameters of twins differentiated according to type of ART are given in $\bullet$ Table 4.

The majority of both first and second twins were in head presentation. The first twins were mostly male and the second twins were often female, but overall, there was a similar number of twins of both sexes. There were considerably more dichorionic twins irrespective of the method of conception.

\section{Twins' condition and outcome}

The majority of twins were in good condition. Only a few twins had illnesses or other complications during pregnancy. There were four stillbirths (one naturally conceived and three conceived by IVF/ICSI). Mean birth weight of the first twins was $2331.53 \pm 591.29 \mathrm{~g}$ ( minimum $=460$; maximum $=3840 \mathrm{~g}$ ) and of the second twins was $2257.27 \pm 604.44 \mathrm{~g}$ ( $\operatorname{minimum}=300$; maximum $=3500 \mathrm{~g}$ ).

Average Apgar score of the first twins was $7.11 \pm 2.06$ while for the second twins it was $7.04 \pm 2.06$. In most cases, both twins (over 50\%) had a good Apgar score (above eight). Thus, the majority of twins had excellent pregnancy outcomes, regardless of the conception method. Poor pregnancy outcomes were recorded more frequently for naturally conceived twins.

\section{Conception method}

The rate of twins conceived by ART was slightly higher $(n=233$; $54.1 \%)$. The most common type of ART used was IVF/ICSI $(\mathrm{n}=164 ; 38.1 \%)$, while IUI was rare $(\mathrm{n}=10 ; 2.3 \%)$.

\section{Correlations between parameters}

and conception method

Both the use of ART and the type of method used were significantly positively correlated with maternal age and delivery type. Women who required more sophisticated ART methods were older $(\rho=0.319 ; \mathrm{p}<0.001)$ and were delivered by cesarean section, usually planned $(\rho=0.523 ; \mathrm{p}<0.001)$. However, as expected, there was a significant negative correlation with parity ( $\rho=-0.364 ; p<0.001)$, since women suffering from infertility usually conceived using ART. Conception by ART was associated with dichorionicity $(\rho=-0.100 ; p=0.036)$. There were no other significant correlations between ART use or type and the other evaluated characteristics of mothers and twins (infertility cause, comorbidities of mothers and twins, treatment, cerclage, pregnancy outcome, fetal lung maturation, fetal gender, etc.). 
Table 2 Parameters of pregnant women and their pregnancies differentiated according to type of ART.

\begin{tabular}{|c|c|c|c|c|c|c|c|}
\hline \multirow[t]{3}{*}{ Parameters } & & \multicolumn{6}{|l|}{ ART type } \\
\hline & & \multicolumn{2}{|l|}{ IVF } & \multicolumn{2}{|l|}{ IVF/ICSI } & \multicolumn{2}{|l|}{ IUI } \\
\hline & & Number & $\%$ & Number & $\%$ & Number & $\%$ \\
\hline \multirow[t]{4}{*}{ Parity } & 1 & 55 & 23.61 & 150 & 64.38 & 10 & 4.29 \\
\hline & 2 & 4 & 1.72 & 13 & 5.58 & 0 & 0.00 \\
\hline & 3 & 0 & 0.00 & 1 & 0.43 & 0 & 0.00 \\
\hline & more & 0 & 0.00 & 0 & 0.00 & 0 & 0.00 \\
\hline \multirow[t]{7}{*}{ Cause of infertility } & male & 14 & 6.01 & 50 & 21.46 & 3 & 1.29 \\
\hline & tubal & 22 & 9.44 & 27 & 11.59 & 4 & 1.72 \\
\hline & immunologic & 0 & 0.00 & 4 & 1.72 & 0 & 0.00 \\
\hline & ovarian insufficiency & 0 & 0.00 & 4 & 1.72 & 1 & 0.43 \\
\hline & endometriosis & 5 & 2.15 & 19 & 8.15 & 1 & 0.43 \\
\hline & combined & 7 & 3.00 & 29 & 12.45 & 0 & 0.00 \\
\hline & unknown & 11 & 4.72 & 31 & 13.30 & 1 & 0.43 \\
\hline \multirow{2}{*}{ PPROM } & no & 41 & 17.60 & 125 & 53.65 & 4 & 1.72 \\
\hline & yes & 18 & 7.73 & 39 & 16.74 & 6 & 2.58 \\
\hline \multirow[t]{2}{*}{ Amniotic fluid } & clear & 53 & 22.75 & 151 & 64.81 & 8 & 3.43 \\
\hline & not clear & 6 & 2.58 & 13 & 5.58 & 2 & 0.86 \\
\hline \multirow[t]{3}{*}{ Delivery type } & vaginal & 7 & 3.00 & 20 & 8.58 & 2 & 0.86 \\
\hline & planned CS & 29 & 12.45 & 86 & 36.91 & 4 & 1.72 \\
\hline & urgent CS & 23 & 9.87 & 58 & 24.89 & 4 & 1.72 \\
\hline \multirow[t]{6}{*}{ Maternal comorbidities } & none & 32 & 13.73 & 94 & 40.34 & 7 & 3.00 \\
\hline & hypertension & 9 & 3.86 & 16 & 6.87 & 2 & 0.86 \\
\hline & diabetes & 3 & 1.29 & 13 & 5.58 & 0 & 0.00 \\
\hline & placental & 0 & 0.00 & 3 & 1.29 & 1 & 0.43 \\
\hline & other & 12 & 5.15 & 21 & 9.01 & 0 & 0.00 \\
\hline & multiple & 3 & 1.29 & 17 & 7.30 & 0 & 0.00 \\
\hline \multirow[t]{5}{*}{ Supportive therapy } & no & 7 & 3.00 & 14 & 6.01 & 2 & 0.86 \\
\hline & progesterone & 2 & 0.86 & 3 & 1.29 & 0 & 0.00 \\
\hline & antibiotics & 7 & 3.00 & 6 & 2.58 & 0 & 0.00 \\
\hline & combined & 37 & 15.88 & 113 & 48.50 & 7 & 3.00 \\
\hline & other & 6 & 2.58 & 28 & 12.02 & 1 & 0.43 \\
\hline \multirow[t]{2}{*}{ Cerclage } & no & 55 & 23.61 & 143 & 61.37 & 9 & 3.86 \\
\hline & yes & 4 & 1.72 & 21 & 9.01 & 1 & 0.43 \\
\hline
\end{tabular}

ART: assisted reproductive technology; IVF: in vitro fertilization; ICSI: intracytoplasmic sperm injection; IUI: intrauterine insemination; PPROM: premature preterm rupture of membranes; CS: cesarean section

\section{Differences in parameters with regard to conception method}

Regarding the use of ART, there were significant differences in patient age $\left(\mathrm{KWX}^{2}=55.909 ; \mathrm{p}<0.001\right)$ and parity $\left(\mathrm{KWX}^{2}=\right.$ 64.600; $\mathrm{p}<0.001)$ as well as delivery type $\left(\mathrm{KW}_{\mathrm{X}}{ }^{2}=136.658\right.$; $\mathrm{p}<0.001)$. When we assessed the type of ART procedure, significant differences were found for PPROM $\left(\mathrm{KW}_{X^{2}}{ }^{2}=6.721 ; \mathrm{p}=0.035\right)$ and patient age $\left(\mathrm{KWX}_{\mathrm{X}}{ }^{2}=10.485 ; \mathrm{p}=0.005\right)$. Patients who had ICSI were older and PPROM was more common. Dichorionic twins were mostly conceived by ART and had better survival rates $\left(K W X^{2}=4.370 ; p=0.037\right)$. Monochorionic twins were conceived either spontaneously or using ICSI. There were no other significant differences between patients who conceived using ART or spontaneously or between ART types with regard to characteristics of mothers and twins and overall outcome of pregnancy.

\section{Relationship model and ROC analysis}

A significant logistic regression equation for the relationship between assessed characteristics of mothers and twins and conception using ART was obtained $\left(\mathrm{X}^{2}=224.820 ; \mathrm{p}=0.001\right.$; total classification $=84.9 \%$ ). Based on the equation it was found that advanced maternal age, the presence of comorbidities and lower parity were the most important predictors for ART conception.
Additionally, twins conceived by ART were more likely to have PPROM and be delivered by cesarean section.

According to results of the ROC analysis, maternal age correctly explained the use of ART for the conception of twins in $70.8 \%$ of cases, parity in $33.7 \%$, chorionicity in $48.7 \%$, and predicted that ART twins would be delivered by cesarean section in $80.6 \%$ of cases ( $\mathbf{O}$ Fig. $\mathbf{1}$ ). When an age of 32.5 years was taken as the cutoff value, the sensitivity of ART use for conception of twins was $68.2 \%$, the specificity was $63.1 \%$, the positive predictive value was $53.2 \%$ and the negative predictive value was $71.6 \%$.

\section{Discussion}

Based on our results it can be stated that the use of ART for conception does not have a significant negative influence on twin pregnancy outcomes. Maternal age, comorbidities and parity all influence the decision to use ART for conception. We have shown that uncomplicated twin pregnancies with successful delivery at term are possible, although currently the majority of twins conceived by ART are delivered by cesarean section.

The literature on the outcome of twin pregnancies, including meta-analyses, has been contradictory [9]. While some studies 
Table 3 Parameters of twins for the whole group and according to type of conception (spontaneous, ART).

\begin{tabular}{|c|c|c|c|c|c|c|c|}
\hline \multirow[t]{3}{*}{ Parameters } & & \multirow{2}{*}{\multicolumn{2}{|c|}{ Whole group }} & \multicolumn{4}{|l|}{ ART } \\
\hline & & & & \multicolumn{2}{|l|}{ No } & \multicolumn{2}{|l|}{ Yes } \\
\hline & & Number & $\%$ & Number & $\%$ & Number & $\%$ \\
\hline \multirow[t]{3}{*}{ I twin presentation } & head & 268 & 62.2 & 122 & 28.31 & 146 & 33.87 \\
\hline & pelvis & 142 & 32.9 & 66 & 15.31 & 76 & 17.63 \\
\hline & other & 21 & 4.9 & 10 & 2.32 & 11 & 2.55 \\
\hline \multirow[t]{3}{*}{ II twin presentation } & head & 222 & 51.5 & 97 & 22.51 & 125 & 29.00 \\
\hline & pelvis & 107 & 24.8 & 52 & 12.06 & 55 & 12.76 \\
\hline & other & 102 & 23.7 & 49 & 11.37 & 53 & 12.30 \\
\hline \multirow[t]{2}{*}{ I twin gender } & male & 226 & 52.4 & 105 & 24.36 & 121 & 28.07 \\
\hline & female & 205 & 47.6 & 93 & 21.58 & 112 & 25.99 \\
\hline \multirow[t]{2}{*}{ II twin gender } & male & 203 & 47.1 & 95 & 22.04 & 108 & 25.06 \\
\hline & female & 228 & 52.9 & 103 & 23.90 & 125 & 29.00 \\
\hline \multirow[t]{6}{*}{ Twins comorbidities } & none & 360 & 83.5 & 163 & 37.82 & 197 & 45.71 \\
\hline & malformations & 16 & 3.7 & 9 & 2.09 & 7 & 1.62 \\
\hline & IUGR & 3 & 0.7 & 2 & 0.46 & 1 & 0.23 \\
\hline & asphyxiation & 13 & 3.0 & 6 & 1.39 & 7 & 1.62 \\
\hline & multiple & 11 & 2.6 & 4 & 0.93 & 7 & 1.62 \\
\hline & other & 28 & 6.5 & 14 & 3.25 & 14 & 3.25 \\
\hline \multirow[t]{2}{*}{ Maturation } & no & 345 & 80.0 & 157 & 36.43 & 188 & 43.62 \\
\hline & yes & 86 & 20.0 & 41 & 9.51 & 45 & 10.44 \\
\hline \multirow[t]{2}{*}{ Chorionicity } & dichorionic & 404 & 93.7 & 190 & 44.08 & 214 & 49.65 \\
\hline & monochorionic & 27 & 6.3 & 8 & 1.86 & 19 & 4.41 \\
\hline \multirow[t]{3}{*}{ Outcome } & excellent & 208 & 25.1 & 99 & 22.97 & 109 & 25.29 \\
\hline & intermediate & 157 & 19.0 & 64 & 14.85 & 93 & 21.58 \\
\hline & bad & 66 & 8.0 & 35 & 8.12 & 31 & 7.19 \\
\hline
\end{tabular}

IUGR: intrauterine growth restriction; ART: assisted reproductive technology

Table 4 Frequency of assessed parameters of twins concerning ART type.

\begin{tabular}{|c|c|c|c|c|c|c|c|}
\hline \multirow[t]{3}{*}{ Parameters } & & \multicolumn{6}{|l|}{ ART type } \\
\hline & & \multicolumn{2}{|l|}{ IVF } & \multicolumn{2}{|l|}{ IVF/ICSI } & \multicolumn{2}{|l|}{ IUI } \\
\hline & & Number & $\%$ & Number & $\%$ & Number & $\%$ \\
\hline \multirow[t]{3}{*}{ I twin presentation } & head & 39 & 16.74 & 102 & 43.78 & 5 & 2.15 \\
\hline & pelvis & 17 & 7.30 & 54 & 23.18 & 5 & 2.15 \\
\hline & other & 3 & 1.29 & 8 & 3.43 & 0 & 0.00 \\
\hline \multirow[t]{3}{*}{ II twin presentation } & head & 37 & 15.88 & 82 & 35.19 & 6 & 2.58 \\
\hline & pelvis & 14 & 6.01 & 38 & 16.31 & 3 & 1.29 \\
\hline & other & 8 & 3.43 & 44 & 18.88 & 1 & 0.43 \\
\hline \multirow[t]{2}{*}{ I twin sex } & male & 32 & 13.73 & 84 & 36.05 & 5 & 2.15 \\
\hline & female & 27 & 11.59 & 80 & 34.33 & 5 & 2.15 \\
\hline \multirow[t]{2}{*}{ II twin sex } & male & 31 & 13.30 & 71 & 30.47 & 6 & 2.58 \\
\hline & female & 28 & 12.02 & 93 & 39.91 & 4 & 1.72 \\
\hline \multirow[t]{6}{*}{ Twins comorbidities } & none & 49 & 21.03 & 140 & 60.09 & 8 & 3.43 \\
\hline & malformations & 0 & 0.00 & 6 & 2.58 & 1 & 0.43 \\
\hline & IUGR & 0 & 0.00 & 1 & 0.43 & 0 & 0.00 \\
\hline & asphyxiation & 4 & 1.72 & 2 & 0.86 & 1 & 0.43 \\
\hline & multiple & 3 & 1.29 & 4 & 1.72 & 0 & 0.00 \\
\hline & other & 3 & 1.29 & 11 & 4.72 & 0 & 0.00 \\
\hline \multirow[t]{2}{*}{ Maturation } & no & 46 & 19.74 & 135 & 57.94 & 7 & 3.00 \\
\hline & yes & 13 & 5.58 & 29 & 12.45 & 3 & 1.29 \\
\hline \multirow[t]{2}{*}{ Chorionicity } & dichorionic & 59 & 25.32 & 145 & 62.23 & 10 & 4.29 \\
\hline & monochorionic & 0 & 0.00 & 19 & 8.15 & 0 & 0.00 \\
\hline \multirow[t]{3}{*}{ Outcome } & excellent & 24 & 10.30 & 80 & 34.33 & 5 & 2.15 \\
\hline & intermediate & 28 & 12.02 & 63 & 27.04 & 2 & 0.86 \\
\hline & bad & 7 & 3.00 & 21 & 9.01 & 3 & 1.29 \\
\hline
\end{tabular}

IUGR: intrauterine growth restriction; IVF: in vitro fertilization; ICSI: intracytoplasmic sperm injection; IUI: intrauterine insemination 


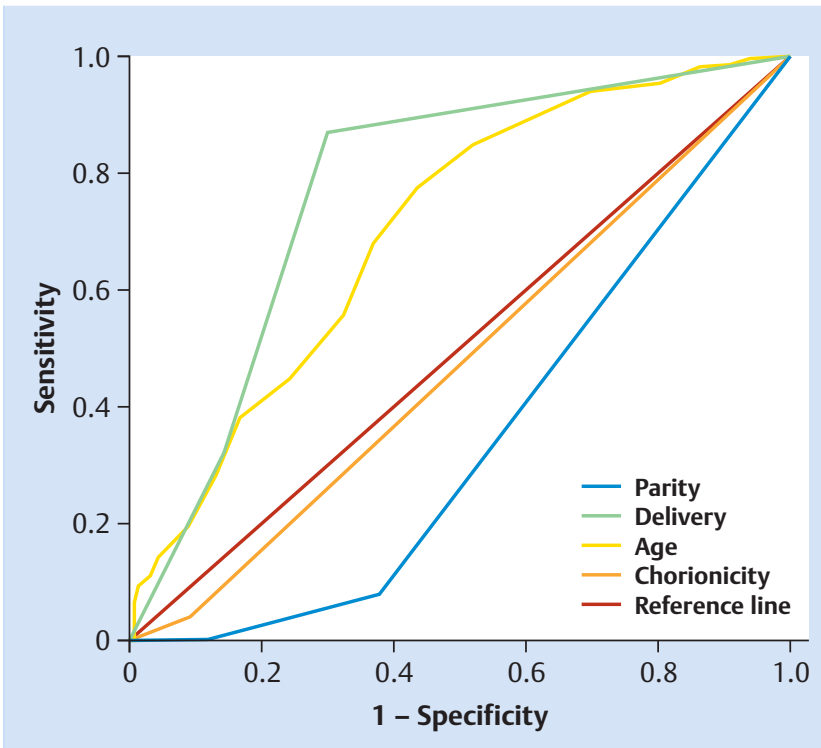

Fig. 1 ROC analysis of maternal age, parity, chorionicity and type of delivery for the prediction of ART conception of twins.

suggest that twins conceived by ART have a higher risk of pregnancy complications, premature birth, low birth weight, and mortality at birth, other studies argue that there is no evidence of a higher incidence of adverse outcomes [10].

Several previous investigations have shown that obstetrical outcomes in ART pregnancies are worse than in the general population, which can be mainly explained by the higher multiple birth rates after ART, which account for the most severe obstetric outcomes [9]. Some researchers, after controlling for maternal age and nulliparity, have provided evidence that twin pregnancies conceived using ART and ovulation induction have an increased risk of gestational diabetes mellitus. The most common complications of pregnancies after ART are bleeding in the first trimester and disproportionate growth of twins [11]. In addition, IVF-conceived pregnancies have been associated with a higher incidence of preterm births and prematurity-related respiratory complications with longer stays in the neonatal intensive care unit [12, 13].

Conversely, our study found no significant differences with regard to pregnancy complications between groups with and without ART. Other researchers have also claimed that, although some antenatal complications are more common in ART twins than in spontaneously conceived twins, the overall prevalence of complications is low and thus their impact on the morbidity and mortality of an individual pregnancy is limited. Pregnancy complications do not contribute to higher rates of premature rupture of membranes or the frequency of IUGR in ART twin pregnancies $[12,13]$. In our population, although delivery mostly occurred during the 36th gestational week, PPROM was also not common. However, PPROM was more common if ICSI was used for conception. Moreover, some data show that the rate of preterm births is similar to that of spontaneously conceived twins and that very preterm deliveries even occurred more frequently with spontaneously conceived twin pregnancies $[14,15]$. It is possible that women with an IVF pregnancy were more compliant with therapy and more likely to take early work leave, both of which could have a positive effect on preventing preterm labor. Hence, in healthy women younger than 45 years of age, twin pregnancies after ART do not require additional antenatal care compared with spontaneously conceived twins [16-18].

The increased risk of congenital malformations associated with ART was not significant in different studies after adjusting for confounding parental factors [19]. We also found that there were no significant malformations in twins as a result of ART procedures.

Our results suggest that twin pregnancies conceived by ART have similar outcomes for both mother and child to outcomes after spontaneously conceived pregnancies, which is consistent with findings in the majority of other studies [19]. We found no difference in birth weight of the first and second twin between groups with and without ART, which is in agreement with other studies [10]. Our findings showed no significant difference in mortality or general condition at birth between twins conceived using ART methods or spontaneously. The majority of twins were in good condition, complications were rare, and the twins usually had an Apgar score $\geq 8$. There were no significant correlations between ART and the evaluated characteristics of twins.

The risk profiles for ART twins and two consecutive ART singletons can be assumed to be very similar. Moreover, the overall consensus, with few exceptions, is that ART twins have neonatal outcomes that are similar to those of infants conceived spontaneously. Some literature reviews reported that ART twins had even better outcomes than spontaneously conceived twins. This might be due to mothers with spontaneously conceived twins having fewer regular check-ups compared to mothers with ART-conceived twins. Studies reported that uncomplicated twin pregnancies with successful delivery at term are possible [20]. This was also confirmed by our study. Therefore, it can be stated that twin pregnancies represent an entirely reasonable option for IVF patients [21].

It remains unclear whether the increased risk of adverse obstetric outcomes after ART is a direct effect of the procedure and the technology or whether it reflects some other factor related to the underlying infertility of the couple. If the problem lies in the ART technology itself, more adverse outcomes would be documented for ART twins, but this has not been the case so far. Some data, including our findings, show that the increased risk for adverse pregnancy outcomes does not depend on the type of ART procedure. These results suggest that perhaps underlying factors associated with the mother's infertility exert more negative effects on children than the ART procedure itself [12,22].

The literature shows that mothers of twins conceived using ART are usually significantly older [23]. This was also the case in our study. However, this observation may indicate a potential bias with regard to maternal age and the number of embryos transferred, since older women are more likely to desire twin pregnancies. Moreover, almost all mothers in different studies were under the age of 40 , and therefore overall study populations are young. This is also due to the fact that there is usually an age limit for performing ART procedures [19].

In some populations, the rate of cesarean sections was slightly, but not significantly, higher in ART pregnancies. In the majority of studies, the most common indication for cesarean section is the presentation of the first twin [13]. In our population, the incidence of cesarean sections was also higher compared to vaginal deliveries, but there was no difference with regard to the method of ART used. In our study cohort, most twins were in head presentation, irrespective of the delivery method. In spontaneously conceived pregnancies, cesarean sections were often done be- 
cause of a previous operative delivery, whereas ART pregnancies were usually the first pregnancy. The majority of our patients were also primiparas. Although most women did not have any pregnancy-related morbidities, almost $90 \%$ received some kind of medication during pregnancy. The increased incidence of cesarean sections and the multiple medications may be due to the patient's and/or physician's concerns regarding pregnancy outcome rather than obstetric indications $[15,23]$.

Finally, it should be noted that this study has some limitations. We did not assess fetal losses in the first trimester. In this investigation we focused on pregnancies that lasted more than 30 gestational weeks. Pregnancies terminated before that period are not currently sufficiently numerous to be analyzed. Further research in this area might be possible in a few years. Our study created an equation showing the relationship between assessed maternal and twin characteristics and the use of ART procedures for conception.

\section{Conclusions \\ $\nabla$}

Maternal age, illnesses and parity can influence the decision whether to use ART for conception. Older women suffering from infertility need more sophisticated ART methods to conceive and generally take multiple medications during pregnancy. Our results suggest that twin pregnancies conceived by ART methods have similar outcomes for both mother and child to those of spontaneously conceived pregnancies. The use of ART for conception does not have a significant negative influence on twin pregnancy outcomes. If IVF/ICSI is used, PPROM is more frequent, and cesarean section is usually the method of delivery for these patients. However, preterm delivery is infrequent irrespective of the conception method. The majority of twins had favorable pregnancy outcomes and good Apgar scores, and complications were rare. Our findings suggest that the transfer of two embryos is safe. Uncomplicated twin pregnancies with successful delivery at term are possible, and ART twins do not require additional antenatal care compared to spontaneously conceived twins.

\section{Conflict of Interest}

Authors declare no conflict of interest.

\section{References}

1 Xing LF, Qian YL, Chen LT et al. Is there a difference in cognitive development between preschool singletons and twins born after intracytoplasmic sperm injection or in vitro fertilization? J Zhejiang Univ Sci B 2014; 15: 51-57

2 Pinborg A. IVF/ICSI twin pregnancies: risks and prevention. Hum Reprod Update 2005; 11: 575-593

3 Black M, Bhattacharya S. Epidemiology of multiple pregnancy and the effect of assisted conception. Semin Fetal Neonatal Med 2010; 15: 306312
4 Schure V, Voigt M, Schild RL et al. Perinatal risks in "late motherhood" defined based on parity and preterm birth rate - an analysis of the German perinatal survey (20th communication). Geburtsh Frauenheilk 2012; 72: 49-55

5 Bohni SC, Roos M, Kurmanavicius J et al. New reference curves on maternal weight gain in twin pregnancy. Geburtsh Frauenheilk 2011; 71: 979-984

6 Domingues AP, Dinis SR, Belo A et al. Impact of induced pregnancies in the obstetrical outcome of twin pregnancies. Fertil Steril 2014; 101: 172-177

7 Murray SR, Norman JE. Multiple pregnancies following assisted reproductive technologies - a happy consequence or double trouble? Semin Fetal Neonatal Med 2014; 19: 222-227

8 Reinhard J, Hanker L, Sanger $N$ et al. Neonatal transfer rate and mode of delivery from 37th week of gestation in a German perinatal center level 1. Geburtsh Frauenheilk 2013; 73: 324-329

9 McDonald SD, Han Z, Mulla S et al. Preterm birth and low birth weight among in vitro fertilization twins: a systematic review and meta-analyses. Euro J Obstet Gynecol Reprod Biol 2010; 148: 105-113

10 Anbazhagan A, Hunter A, Breathnach FM et al. Comparison of outcomes of twins conceived spontaneously and by artificial reproductive therapy. J Matern Fetal Neonatal Med 2014; 27: 458-462

11 Gleicher N, Bard DH. Mistaken advocacy against twin pregnancies following IVF. J Assist Reprod Genet 2013; 30: 575-579

12 Nassar AH, Usta IM, Rechdan JB et al. Pregnancy outcome in spontaneous twins versus twins who were conceived through in vitro fertilization. Am J Obstet Gynecol 2003; 189: 513-518

13 Adler-Levy Y, Lunenfeld E, Levy A. Obstetric outcome of twin pregnancies conceived by in vitro fertilization and ovulation induction compared with those conceived spontaneously. Euro J Obstet Gynecol Reprod Biol 2007; 133: 173-178

14 Szymusik I, Kosinska-Kaczynska K, Bomba-Opon $D$ et al. IVF versus spontaneous twin pregnancies - which are at higher risk of complications? J Matern Fetal Neonatal Med 2012; 25: 2725-2728

15 Moini A, Shiva M, Arabipoor A et al. Obstetric and neonatal outcomes of twin pregnancies conceived by assisted reproductive technology compared with twin pregnancies conceived spontaneously: a prospective follow-up study. Eur J Obstet Gynecol Reprod Biol 2012; 165: 29-32

16 Yang H, Choi YS, Nam KH et al. Obstetric and perinatal outcomes of dichorionic twin pregnancies according to methods of conception: spontaneous versus in-vitro fertilization. Twin Res Hum Genet 2011; 14 : 98-103

17 Vasario E, Borgarello $V$, Bossotti $C$ et al. IVF twins have similar obstetric and neonatal outcome as spontaneously conceived twins: a prospective follow-up study. Reprod Biomed Online 2010; 21: 422-428

18 Mohammed ABF, Abdel-Maaboud M. Obstetric and neonatal outcomes of IVF versus spontaneously conceived dichorionic twins. Middle East Fertil Soc J 2012; 17: 231-235

19 Fan C, Sun Y, Yang J et al. Maternal and neonatal outcomes in dichorionic twin pregnancies following IVF treatment: a hospital-based comparative study. Int J Clin Exp Pathol 2013; 6: 2199-2207

20 Bamberg C Fotopoulou C, Neissner P et al. Maternal characteristics and twin gestation outcomes over 10 years: impact of conception methods. Fertil Steril 2012; 98: 95-101

21 Jauniaux E, Ben-Ami I, Maymon R. Do assisted-reproduction twin pregnancies require additional antenatal care? Reprod Biomed Online 2013; 26: 107-119

22 Sekhon LH, Gerber RS, Rebarber A et al. Effect of oocyte donation on pregnancy outcomes in in vitro fertilization twin gestations. Fertil Steril 2014; 101: 1326-1330

23 Fotopoulou C, Neissner P et al. Maternal characteristics and twin gestation outcomes over 10 years: impact of conception methods. Fertil Steril 2012; 98: 95-101 